\title{
Толкование Судом ЕС положений о конкуренции, содержащихся в Статье 81 Договора об образовании Европейского Сообщества
}

Горбачев В.A. *

Правила регулирования конкурентных отношений в Европейском Союзе содержатся в Римском договоре об учреждении Европейского экономического сообщества 1957 года. Правила конкуренции в ЕС подразделяются на три вида: 1) правила, применяемые к предприятиям; 2) антидемпинговые нормы; 3) правила, запрещающие предоставление государственной помощи предприятиям в виде субсидий и иных компенсационных пошлин 1 .

Эти правила главным образом сосредоточены в статьях 81 и 82 Договора об образовании ЕС. Статья 81 применяется к договорным формам нарушения конкурентных отношений. А статья 82 устанавливает общий запрет на злоупотребление доминирующим положением на рынке.

Очевидно, что применение на практике этих статей носит комплексный характер и в ряде случаев нормы права, которые содержатся в этих статьях, требуют определенного разьяснения и комментариев со стороны уполномоченных антимонопольных и судебных органов ЕС. Сложившаяся в ЕС правоприменительная и судебная практика показывает неоднозначность терминов и определений, которые используются в антимонопольном регулировании и поддержании «нормальной» конкуренции как таковой на рынках стран-членов ЕС. В этой связи возникает необходимость более глубокого исследования судебной и правоприменительной практики ЕС, поскольку опыт решения многих правовых проблем и задач, которые преследует законодательство о конкуренции ЕС, может быть с успехом имплементировано и в нашей стране.

В настоящей статье рассматриваются подробно лишь толкования понятий содержащихся в статье 81 , поскольку она является основой

\footnotetext{
* Горбачев Вячеслав Александрович - соискатель кафедры международного частного и гражданского права МГИМО (У) МИД РФ.

1 Зименкова О.Н. Регулирование конкурентной монополистической деятельности // Гражданское и торговое право зарубежных государств: Учебник / Отв.редактор Е.А. Васильев, А.С. Комаров. Т. 1. М.: Международные отношения, 2004. -287-288 с.
} 
для пресечения наиболее распространенной формы нарушения конкурентных отношений - договорной.

Структурно 81 статья может быть представлена следующим обра30M:

Пункт 1 статьи устанавливает возможные типы запретов на действие или поведение двух и более сторон, заключивших соглашение.

Пункт 2 предусматривает, что определенные соглашения, решения ассоциаций или ограничительная практика предприятий автоматически считаются недействительными.

Пункт 3 предусматривает возможность изъятий из установленных ограничений.

Следует отметить, что установление факта нарушения или ненарушения тем или иным предприятием статьи 81(1) зависит от многочисленных факторов, которые учитываются Европейской Комиссией и национальными антимонопольными органами при рассмотрении заключенного соглашения. Это такие факторы, как обеспечение нормального функционирования и сохранения единого рынка ЕС, недопущение чрезмерной экономической или финансовой концентрации, недопущение чрезмерного обогащения и т.п.

Важность учета этих факторов и постоянное изменение их содержания не позволило Суду ЕС и Суду первой инстанции ${ }^{2}$, а также Европейской Комиссии дать общее толкование статей 81 и 82, как это делают национальные суды стран-членов ЕС. Например, это сделал суд Англии, предоставивший комментарии по новому принятому закону о Конкуренции ${ }^{3}$. Помимо этого, используемый судебной и правоприменительной практикой ЕС телеологический метод 4 , предус-

2 Суд первой инстанции (СПИ) был создан в соответствии с Единым Европейским Актом 1986 года для того, чтобы в определенной степени разгрузить и облегчить с административной точки зрения работу Суда ЕС. Суду Первой Инстанции подсудны дела меньшей значимости. Основой для существования и деятельности Суда Первой Инстанции является статья 225 Римского договора. Втечение последнего времени значительно возросла роль данного Суда, что в свою очередь нашло отражение в Ниццском договоре 2001 года. В частности, статья 220 Договора говорит о том, что Суд ЕС и Суд Первой Инстанции обеспечивают в рамках своей соответствующей компетенции соблюдение права при толковании и применении настоящего Договора.

${ }^{3}$ EC Competition Law, D.G. Goyder, p. 60.

4 Телеологический метод - один из общепринятых методов толкования законов. Телеологическое или как еще его принято называть «целевое толкование» - это уяснение смысла закона в связи с его целевым назначением (если закон в своем буквальном смысле не применим в конкретном случае, следует толковать его в том смысле, который 
матривающий толкование всех статей Договора об образовании ЕС в общем контексте заключенного соглашения, не допускает предоставления отдельных комментариев по статьям Договора вне его основного контекста. Но, тем не менее, практика применения антимонопольного законодательства ЕС потребовала прояснения отдельных терминов и значений, содержащихся в Статье 81.

\section{Нарушение статьи 81(1)}

Для установления факта нарушения статьи 81(1) от Европейской Комиссии и Суда ЕС потребовалось прояснение и толкование следующих терминов и определений:

- понятие: «предприятие»;

- понятие: «все соглашения, решения ассоциации предприятий и ограничительная практика»;

- понятие: «которое может оказать воздействие на торговлю между государствами-членами»;

- понятие: «которые имеют своей целью или результатом предотвращение, ограничение или нарушение конкуренции внутри общего рынка».

\section{1. Толкование понятия: «предприятие»}

Необходимость четкого понимания содержательного значения этого термина обусловлена рядом спорных решений, принимаемых Европейской Комиссией и Судом ЕС, поскольку именно «предприятие» согласно европейскому праву конкуренции является основным субъектом конкурентных отношений. Материальные нормы права конкуренции ЕС не содержат однозначного определения того, что такое «предприятие».

В европейской юридической теории предпринимались неоднократные попытки дать исчерпывающее определение того, что оно включает в действующем праве и что подразумевает законодатель под этим термином для целей законодательства о конкуренции. Но однозначного и наиболее часто используемого в европейской юридической теории и практике определения этого значения невозможно обнаружить.

Представляется, что разрешение этого вопроса лежит в двух плоскостях - лингвистической и смысловой (содержательной), - то есть,

данный закон имеет на момент его применения). Данный метод толкования широко используется в общеевропейской судебной практике. 
важно понимать какое значение это слово несет именно в праве конкуренции.

С формально-лингвистической точки зрения, слово undertaking на русский язык переводится как «предприятие». В английском языке также можно подобрать и иные синонимы для этого слова: company (компания, предприятие), firm (фирма), enterprise (предприятие), business (бизнес, предприятие). Эти синонимы, так или иначе, ассоциируются как в русском языке, так и в английском со словом «предприятие» и употребление этих слов с этим же значением можно обнаружить в ряде законов европейских государств. Например, в праве Франции используется слово «еnterprise», которое имеет такое же значение, как и английское слово «undertaking». Для сравнения, в праве нашей страны используется слово (термин) «предприятие» или «юридическое лицо».

Если говорить о смысловом значении, которое имеет это слово, то следует отметить, что под «предприятием» в европейском праве конкуренции понимаются как физические, так и юридические лица. Судом ЕС и Судом первой инстанции предпринимались неоднократные попытки выработать содержательное значение термина «предприятие». Например, вот одно из самых первых определений, данных Судом EC, которое содержится в деле Mannesman v. High Authority5: «предприятие - это единая организация личных материальных и нематериальных элементов, переданных автономному (самостоятельному) юридическому лицу, преследующему установленную долгосрочную экономическую цель». Понятно, что «предприятие» должно обладать предусмотренными законом правами и обязанностями для того, чтобы полноценно осуществлять взаимодействие с другими субъектами экономических отношений и выполнение своих функций, для которых оно было создано.

Вышеприведенное определение Суда ЕC получило широкое применение в судебной практике за рядом исключений. Эта концепция, например, не применяется к государству при осуществлении им своих прямых функций (за исключением выполнения коммерческих функций), а также к организациям, которые не ставят своей целью осуществление экономической деятельности или координацию такой деятельности. В последнем случае, в частности речь может идти о религиозных организациях и объединениях, а также о гуманитарных

5 Mannesman v. High Authority Case 19/61 [1962] ECR 357,371. 
или экологических организациях. Быть вовлеченным в экономическую деятельность, - является обязательным и самым главным условием, но получение прибыли вовсе не является важным условием в этой связи ${ }^{6}$.

Однако содержательное значение этого термина, используемое для целей конкурентного права, наиболее всеобъемлюще и более удачно сформулировано в ином решении Суда ЕC в деле Hofner and Elser v. Macrotron GmbH case C-41/90 [1993] 4 CMLR 306: «концепция предприятия включает каждое образование, вовлеченное в экономическую деятельность, вне зависимости от юридического статуса этого образования и способа его финансирования».

Из этого судебного решения следует, что какое-либо физическое лицо равно также как и юридическое, может быть признано, для целей законодательства о конкуренции, «предприятием» если оно оказывает, то или иное воздействие на конкуренцию на соответствующем (релевантном) рынке. Следовательно, Европейская Комиссия будет принимать в расчет не юридический статус (форму образования) субъекта экономической деятельности, а его воздействие на рынок и сложившуюся на нем экономическую ситуацию и конкурентные отношения.

Практика Суда ЕС свидетельствует, что ключевым элементом при определении понятия предприятия является не природа формы образования предприятия, а суть деятельности, которую оно осуществляет ${ }^{7}$. Следует отметить, что действительно в решениях Суда можно встретить немало фактов, когда физическое лицо рассматривалось как «предприятие» и в отношении его действий на соответствующем рынке принимались ограничения или налагались штрафы. Так в деле UNITEL 78/516/EEC(1978) OJ L254/40 оперные певцы рассматривались как «предприятие» и тем самым подпадали под действие антимонопольного законодательства.

Также нужно указать на то, что под действие европейского антимонопольного законодательства может попасть деятельность и некоммерческих организаций, и это означает, что само существование и деятельность таких организаций также в определенных случаях подпадает под термин «предприятие» даже несмотря на то, что по существующим законам ЕС (как и России) основной целью деятель-

6 EC Competition Law, D.G. Goyder, p. 60.

7 EC Competition Law, D.G. Goyder, p. 60. 
ности некоммерческих организаций не может являться предпринимательская деятельность с целью получения прибыли как таковой, т.е. промысел.

Решение вопроса о том, следует ли рассматривать ту или иную некоммерческую организацию в качестве «предприятия» для целей законодательства о конкуренции, будет решаться в каждом отдельно взятом случае.

Отдельного рассмотрения в этой связи требует вопрос, связанный с положением агента. Агентами, согласно европейскому законодательству могут выступать как отдельные физические лица, так и предприятия. В частности, нас интересуют ситуации, когда агент будет рассматриваться в качестве предприятия, и когда к нему будет применяться статья 81. Очевидно, для того чтобы не применялась статья 81 Договора об образовании ЕС, будет не достаточно, если физическое лицо или предприятие действует лишь по названию как «агент».

Положение о вертикальных соглашениях ${ }^{8}$ вводят такое понятие как «подлинный» агент. Согласно этому определению, агент остается «подлинным» до тех пор, пока он принимает на себя ограниченный риск и не инвестируют свои собственные средства в интересах уполномочившего его принципала. Согласно сложившейся в ЕС практике, агент будет квалифицирован как «предприятие», если объем и тип услуг, который он оказывает принципалу и от его имени, выходит за рамки обычно оказываемых услуг в этой связи.

Обычно агент ограничен принципалом территорией, на которой он может действовать от его имени и кругом клиентов, которым он может продавать соответствующий товар или услуги, а также агент ограничен в цене и условиях продажи или предоставлении тех или иных товаров или услуг. Перечисленные выше условия позволяют квалифицировать агента как «подлинного». Во всех же остальных случаях отсутствие или невыполнение данных условий позволяет антимонопольным органам классифицировать агента как «предприятие» и применять к нему статью 81.

Для целей определения понятия «предприятие» также необходимо отметить, что согласно ранее действующему Регламенту № 17/62 и новому Регламенту № 1/2003, которые вместе устанавливали 10 процентный уровень контроля соответствующего товарного рынка тем или иным предприятием, подразумевается, что, одним «предприятием»

8 Guidelines on vertical restrains [2000] OJ C291/1 [2005] 5 CMLR 1074. 
считается не только основное или головное предприятие, но также его дочерние предприятия и отделения, т.е. подсчет и установление размера занимаемого рынка должен осуществляться с учетом совокупной доли, занимаемой на рынке всех предприятий, имеющих одновременно общую экономическую и организационно-правовую взаимосвязь.

Данный подход заимствуют и национальные антимонопольные законодательства. Например, британскими законодателями, которые также включили в Закон о конкуренции 1998 года сходные положения, закрепленные в вышеупомянутых регламентах относительно метода подсчета занимаемого соответствующего рынка и определение «предприятия».

2. Толкование понятия: «сговор между предприятиями: «все соглашения, решения ассоциации предприятий и ограничительная практика»

Из положения статьи 81(1) очевидно, что, она применяется, вопервых, к «соглашениям» двух или более предприятий, во-вторых, к «решениям ассоциации предприятий», в-третьих, к «ограничительной практике/деятельности предприятий». Основным назначением статьи 81 является скорее выявление и пресечение негативного экономического воздействия на общий рынок от заключенного между сторонами соглашения (соглашения, решения ассоциации и ограничительная практика), нежели контроль за соблюдением юридической формы как таковой, в которую облекают предприятия такое соглашение. В деле La Technique Miniere v. Mashinenbau Ulm GmbH Суд ЕС постановил, что осуждение любой ограничительной практики будет зависеть, с одной стороны, не столько от юридической сути заключенного соглашения, сколько от содержания экономических отношений и оказания воздействия на торговлю между государствами-членами $\mathrm{EC}$, а с другой стороны, от уровня развитости конкурентных отношений на соответствующем рынке 9 .

а) соглашения между предприятиями: разработчики статьи 81 понимали, что формы сотрудничества между предприятиями могут носить различные формы и способы, и поэтому они, с точки зрения законодательной техники, применили довольно широкое понятие «соглашение» между предприятиями. Понятно, что,

9 Mark Furse, Competition Law of the UK and EC, p. 111. 
прежде всего, под это понятие подпадают любые письменные соглашения (договоры), заключенные между предприятиями. Также под понятие «соглашение» подпадают любые устные, неформальные договоренности, заключенные между сторонами. В деле National Panasonic ${ }^{10}$ Европейская Комиссия пришла к заключению, что соглашение между сторонами существует, как в случае решения, определяющего поведение для обеих сторон, так и в случае совместного решения сторон отказаться (воздержаться) от тех или иных действий на соответствующем рынке.

Что составляет понятие «соглашение» для целей статьи 81(1), является в течение многих лет спорным вопросом в прецедентном праве ЕС. Единственно, что бесспорно, так это то, что соглашение не обязательно должно быть оформлено письменно. Устные, неформальные и джентльменские соглашения, подпадают под действие статьи 81(1). Единственное, что требуется для того, чтобы соглашение подпадало под действие статьи 81(1) - так это согласие между двумя и более предприятиями, которое иначе также называется «совпадение воли сторон». Понятно, что такое соглашение может быть только двухсторонним или многосторонним ${ }^{11}$.

В этой связи у Европейской Комиссии, в чьи обязанности входит доказательство нарушения статьи 81, возникают сложности, поскольку довольно трудно определить, насколько именно заключенное соглашение между сторонами, а не складывающаяся экономическая конъюнктура на том или ином рынке, нарушает конкурентные отношения.

Определение того, подпадает ли соглашение под действие статьи 81(1) или нет, является прерогативой Суда, а не самих предприятий, заключивших такое соглашение ${ }^{12}$. В этой связи, в праве конкуренции ЕС есть несколько судебных решений и решений Европейской Комиссии, которые являются базовыми для определения того, являются ли заключенные соглашения незаконными и какие элементы должны быть в соглашении, для того, чтобы Суд и административные органы признали его незаконным. К таким решениям можно отнести: Consten and Grundig v. Commission ${ }^{13}$; Ford Werke v. Commission ${ }^{14}$;

\footnotetext{
10 National Panasonic 82/398 (1986) OJ L 345/28.

11 EC and UK Competition Law. Commentary, Cases and Materials. Maher M. Dabbah,. p. 59.

12 EC Competition Law, D.G. Goyder, p. 66.

13 Commission Decision (64/556/EEC), OJ 2545/64, 1964; [1964] CMLR 489.

14 Case 25 and 26/84 [1985] 3CMLR 528.
} 
Bayer AG v. Commission ${ }^{15}$; AEG Telefunken v. Commission ${ }^{16}$; Sandoz Prodotti Farmaceutici SpA v. Commission ${ }^{17}$ и некоторые иные решения Суда ЕС и СПИ.

Но наибольший интерес для понимания того, что подразумевается под понятием «соглашение» в праве конкуренции ЕС, представляет дело Bayer AG v. Commission. Это решение основано на ряде дел, которые названы выше, а также оно содержит и иные актуальные заключения Суда, которые не вошли в принятые решения по указанным делам.

В деле Bayer AG v. Commission Суд первой инстанции указал на то, что, концепция понятия «соглашение» основывается прежде всего на наличии совпадения воли по меньшей мере между двумя сторонами.

Суд также сделал акцент на том, что должно быть проведено различие между ситуациями, в которых предприятие приняло по-настоящему одностороннее решение и ситуациями, в которых одностороннее решение является очевидным, т.е. может быть ложным или прикрытием. Соответственно, в тех случаях, когда решение по-настоящему является односторонним - оно не подпадает под действие статьи 81(1).

В этом случае может быть:

a) предоставлено изъятие в соответствии со статьей 81(3);

b) соглашение может подпасть по действие статьи 82 ;

c) соглашение может быть рассмотрено в соответствии со статьей 28 Договора об образовании ЕС (меры, принимаемые государствами-членами ЕС, ограничивающие свободное движение товаров в рамках общего рынка). В пункте 70 своего решения Суд первой инстанции постановил: «попытка использования статьи 81(1) для наказания предприятия, не занимающего доминирующее положение на рынке, которое отказалось поставлять товар оптовым продавцам с целью предотвращения параллельного импорта, однозначно не требует применения статьи 81. В этом случае должна быть применена статья 28. Но если параллельный импорт ограничивается односторонними действиями предприятия, занимающим доминирующее положение на рынке, то должна быть применена статья 82.

Определяющим в применении статьи 81 или статьи 82 является наличие соглашения между сторонами. Соответственно, если оно есть,

\footnotetext{
15 Case T-41/96 [2000] ECR II-3383; [2001]4 CMLR 4.

16 Case 107/82 [1983] ECR 3151, [1984] CMLR 325 (ECJ).

17 Case 277/87 [1990] ECR I-45 (ECJ).
} 
то применяется статья 81, а если оно отсутствует, то должна быть применена статья 82.

В случаях же, когда одностороннее решение является лишь прикрытием или попросту ложным, то должна применяться статья 81(1).

Также Суд перовой инстанции постановил, что для того чтобы соглашение подпадало под действие статьи 81(1) достаточно изъявления воли сторон о намерении вести себя на том или ином рынке особым способом. Относительно же формы, в которую может быть обличена (выражена) воля сторон, то достаточно всего лишь, что бы стороны придерживались условий этого соглашения, т.е., вели себя обусловленным образом.

С другой стороны, Суд первой инстанции постановил, что соглашение не должно подпадать под действие статьи 81(1), если производитель в одностороннем порядке принял решение в рамках общих заключенных с дилерами договоров (например, в рамках обычных договоров о распространении/сбыте продукции), если только это решение не содержит необходимости подтверждения (принятия) со стороны дилеров принятого одностороннего решения в обусловленной явно выраженной или подразумеваемой этим производителем манере или форме. То есть, данное решение означает, что если производитель принимает односторонние решения, то сторона, получившая эти решения, должна их подтвердить особым, предусмотренным образом. Подтверждением может быть: приложение печатей или штампов или поведение на рынке особым, требуемым и обусловленным между сторонами образом.

Если же сторона, получившая одностороннее решение от производителя, не подтверждает своего согласия действовать предложенным ей образом, а одностороннее решение продолжает действовать, то решение этой стороны может подпасть под действие статьи 82, которая запрещает ограничение параллельного импорта (дело Bayer AG v. Commission, решение Суда первой инстанции, пункт 101).

Отдельно следует сказать о решении Суда ЕС в деле Consten and Grundig v. Commission. В своем апелляционном иске стороны пытались оспорить решение Европейской Комиссии о применении к их соглашению статьи 81(1) на том основании, что эта статья применяется только к соглашениям горизонтального типа, а поскольку заключенное между ними соглашение было вертикального типа, то статья 81(1) не должна применяться. 
Действительно, Grundig являлся производителем бытовой техники, a Constent был в то время эксклюзивным дистрибутором продукции компании Grundig во Франции. Тем не менее, Суд ЕС счел доводы юристов сторон неосновательными и принял решение, что статья 81 применяется как к соглашениям горизонтального типа, так и к соглашениям вертикального типа.

Практика применения антимонопольного законодательства ЕС показывает, что очень часто такого рода ограничительные соглашения оформляются/содержатся не в виде отдельного договора или решения, а как отдельный пункт общего соглашения о сотрудничестве, например, когда речь идет о сотрудничестве вертикального типа между производителями и дистрибьюторами товара. И в этой связи возникает очень важный вопрос - должна ли в этом случае Европейская Комиссия принимать отдельное решение по каждому пункту договора?

В деле Ford Werke v. Commission Суд ЕС постановил, что Европейская Комиссия не должна выносить решение по отдельному пункту договора, если этот договор в целом нарушает статью 81(1). Ford Werke потребовал, чтобы Европейская Комиссия определила каждый пункт договора, который нарушает статью 81(1), а затем рассмотрела каждое нарушение в отдельности, с учетом всех релевантных факторов, включая четыре условия предоставления изъятия, предусмотренных статьей 81(3). Тем не мене, Суд ЕС постановил, что Европейской Комиссией должен быть использован более общий подход при рассмотрении дел такого рода и не удовлетворил требования юристов этой компании ${ }^{18}$.

b) решения ассоциации предприятий: торговые и экономические ассоциации играют важную роль в экономической жизни Европейского Союза, вследствие чего разработчики Римского договора специально выделили ассоциации в отдельную категорию. Что же понимается под термином «ассоциации» для целей законодательства о конкуренции? Прежде всего, очевидно, что «ассоциация» - это независимое объединение, созданное для реализации и достижения определенных целей создавших ее учредителей (независимых субъектов экономической деятельности) или участников. Также очевидно, что статья 81(1) применяется к ассоциациям, которые, прежде всего, созданы для реализации экономических или коммерческих интересов.

Чтобы деятельность ассоциации подпадала под статью 81(1), совсем не обязательно, чтобы эта ассоциация была зарегистрирована и сущес-

18 EC Competition Law, D.G. Goyder, p. 70. 
твовала как независимое юридическое лицо, т.е., действие статьи 81(1) распространяется на решения ассоциации, которая вообее может быть не зарегистрирована официально как юридическое лицо. Если ассоциация официально не зарегистрирована, то решение Европейской Комиссии распространяется на всех членов, участвующих в ней. Если же ассоциация официально зарегистрирована, то решение Европейской Комиссии будет затрагивать саму ассоциацию и ее отдельных членов.

Ассоциацией также может выступать любое профессиональное объединение или организация, кооперативы и иные формы торгового объединения, которые обычно встречаются в агропромышленном секторе и которые структурно отличаются от понятия «ассоциация» в его классическом виде, но выполняют те же самые функции - peaлизация политики в сфере купли-продажи товаров.

Другой немаловажный критерий, существующий в этой связи - это то, что такая ассоциация должна не просто существовать, а именно оказывать определенное воздействие на торговлю между государствами-членами ЕС. Также важно отметить, что не все ассоциации автоматических подпадают под действие статей 81 и 82. Так, например, ассоциации работодателей или торгово-промышленные палаты не подпадают под действие этих статей, до тех пор, пока они не осуществляют конкретную экономическую деятельность ${ }^{19}$.

Что же касается непосредственного вопроса о «решении ассоциации», то здесь можно отметить следующее: «решением» признается любая резолюция уполномоченного органа ассоциации, устанавливающая ограничения или обязательства на ее членов, которая обладает эффектом, ограничивающим свободу действия членов ассоциации. Эти решения могут касаться непосредственно субъектов экономической деятельности, с которыми работает член ассоциации, в отношении которого принято решение, а также касаться поведения на рынке этого члена ассоциации.

Также «решением» могут признаваться и сами правила или устав ассоциации, даже если они не противоречат статье 81. Решения, которые заключены между двумя и более ассоциациями, подпадают под понятие «соглашение» между предприятиями статьи 81(1).

с) ограничительная деловая практика/деятельность предприятий: практика развития современных экономических отношений показывает, что для достижения цели по повышению прибыли неза-

19 EC Competition Law, D.G. Goyder, p. 79. 
конным путем, т.е. в данном случае - путем ограничения или искажения конкурентных отношений, субъектам экономических отношений - предприятиям совсем не обязательно вступать в формальные договорные отношения между собой. Эффект финансово-экономической концентрации может быть достигнут без наличия каких-либо внешних правовых атрибутов или элементов (доказательств). В этом, собственно говоря, и заключена вся сложность вопроса по установлению факта нарушения антимонопольного законодательства путем осуществления согласованных, ограничительных действий.

Термин «ограничительная торговая практика предприятий» в европейское право конкуренции пришел из антимонопольного законодательства США. Дело в том, что на момент разработки Римского договора в 1957 году, ни одно из будущих государств-членов ЕС в своем национальном антимонопольном законодательстве не содержало такого понятия или определения. Более того, даже судебная практика этих государств не знала примеров или случаев рассмотрения подобных дел и вынесения каких-либо решений по ним.

Даже, несмотря на появление этого термина в Римском договоре 1957 года, первое судебное решение и довольно ограниченное его толкование появилось в европейской судебной практике лишь в 1972 году в деле Imperial Chemical Industries v. Commission (Dyestuffs) ${ }^{20}$. Включение этого термина в Римский договор 1957 года без сомнения может быть связано с влиянием антитрестовского законодательства США, где концепция «ограничительная торговая практика» была известна, как по отношению к горизонтальным, так и к вертикальным соглашениям $^{21}$. Также известны случаи, когда Европейская Комиссия в своих решениях делала ссылки на судебные решения федеральных судов США. Например, дело Dyestuffs v. Commission пункт 38.

Как и в случае с понятием «соглашение» термин «ограничительная деловая практика» довольно широко трактуется в европейской теории права конкуренции. Более того, форма соглашения или практики является менее важной, чем экономический эффект, который оказывается на рынок. Формальный подход не поможет достижению целей, которые преследует право в этой связи ${ }^{22}$.

\footnotetext{
20 Case ICI v. Commission 48/69 [1972] CMLR 557.

21 EC Competition Law, D.G. Goyder, p. 72.

22 Competition Law and Policy in the European Union and United Kingdom, Barry J. Rodger \& Angus MacCulloch. p. 131
} 
В Европейской теории права конкуренции, при определении понятия «ограничительная деловая практика предприятий» ссылка делается на два самых важных в этой связи решения Суда ЕС. Это определение Суда по делу ICI v. Commission от 1972 года и определение, данное Судом, по делу Sugar Cartel Case от 1975 года.

В своем самом первом определении, данном в деле ICI v. Commission Суд ЕС истолковал следующим образом понятие «ограничительная деловая практика»: «это форма координации между предприятиями, которая еще не достигла уровня договорных отношений, но которая, тем не менее, на практике замещает сотрудничество, носящее угрозу конкурентным отношениям».

В параграфе 68 решения Суд ЕС указал на то, что такое сотрудничество является «ограничительной деловой практикой», если оно позволяет предприятиям консолидировать имеющиеся позиции на соответствующем рынке в ущерб эффективной свободе перемещения товаров в рамках общего рынка, а также в ущерб свободе права выбора потребителями поставщиков.

Позднее, в 1975 году в деле Sugar Cartel, Суд ЕС подтвердил свое первое данное определение, расширив его и указав на необходимость при рассмотрении подобных дел Европейской Комиссией учитывать в целом все характеристики соответствующего рынка: «концепция «ограничительная деловая практика» относится к форме координации между предприятиями, которая не имеет такой стадии или состояния как надлежащим образом заключенное соглашение, и которая сознательно ставит под угрозу конкурентные отношения путем сотрудничества между предприятиями, приводящими к конкурентным условиям, не соответствующим нормальным условиям рынка с учетом особенностей товара, важности и количества предприятий, действующих на этом рынке, также как, размера и природы указанного рынка».

Причиной вынесения более расширенного толкования концепции «ограничительной практики» стало возникновение ситуации, когда необходимо было отделить «разумные» действия предприятий по реагированию или корректировке своего поведения на рынке, в соответствии со складывающейся объективной ситуацией на соответствующем рынке, от ситуаций, когда изменение поведения предприятия вызвано осуществлением согласованных действий с другим предприятием.

В целях обеспечения гарантирования правильно принятого решения, ограничительная торговая практика часто рассматривается Евро- 
пейской Комиссией как альтернативный вариант даже в тех случаях, когда также существует определенного типа соглашение между предприятиями ${ }^{23}$.

\section{3. Толкование понятия: «оказание воздействия на торговлю} между государствами-членами»

Значение этого термина заключено в том, что он служит разграничительной линией между применением европейского права конкуренции и национального антимонопольного законодательства государствчленов ЕС. То есть, если заключенное между сторонами соглашение не воздействует негативным образом на конкурентные отношения между государствами - членами ЕС, то статья 81(1) не должна быть применена к этому соглашению.

В этой связи, Европейская Комиссия, при рассмотрении подобных соглашений очень часто ссылается на судебную практику, которая по ее мнению является единственным источником объективного определения того, насколько заключенное соглашение подпадет под действие статьи 81(1). И в этом смысле наиболее показательным является дело $\mathrm{STM}^{24}$ и определение, данное по нему Судом: «для того, чтобы это требование было выполнено (т.е. возможность определения того, подпадает ли или нет заключенное соглашение под действие статьи 81(1), должна существовать возможность предвидеть с достаточной степенью вероятности, на основе ряда объективных правовых факторов или на основе фактов, что рассматриваемое соглашение может оказать воздействие, как прямое, так и косвенное, фактическое или потенциальное на торговлю между государствами-членами ЕС».

На основе судебных решений, которые были приняты именно по делам этой категории, Европейская Комиссия в 2004 году издала Положение об оказании воздействия на торговлю между государствамичленами $\mathrm{EC}^{25}$. Это Положение дает толкование таких важных в этой связи определений, как:

a) понятие «концепция торговли между государствами-членами ЕС»: концепция «торговли» не ограничивается традиционным обменом товаров и услуг между государствами. Эта концепция носит более

${ }^{23}$ EC Competition Law, D.G. Goyder, p. 67.

${ }^{24}$ Societe Technique Miniere (STM) v. Mashinenbau Ulm GmbH: 56/65 [1966] ECR 235, [1966] CMLR 357 (ECJ).

25 Guidelines on the effect on trade OJ (2004) C101/81. 
широкий характер и затрагивает любое трансграничное экономическое сотрудничество. Такая интерпретация «торговли» соответствует основополагающей цели Римского Договора - создание условий для свободного перемещения товаров, услуг, лиц и капиталов ${ }^{26}$. Концепция «торговли» также включает в себя соглашения или практику, которая воздействует на конкурентную структуру рынка. В данном случае речь идет об устранении конкурентов или создании условий для их устранения или ограничения их деятельности.

b) понятие «может оказать воздействие»: функция этого понятия заключена в том, чтобы определить природу или суть воздействия на торговлю между государствами - членами ЕС. И в этой связи Судом ЕС разработаны два теста. Первый тест касается непосредственного воздействия на торговлю, а второй, как выше уже было сказано (пункт (a)), относится к соглашениям или практике, которая воздействует на конкурентную структуру рынка. Последний тест, как и первый, также предназначен для установления того, может ли быть применено европейское право конкуренции или национальное антимонопольное право. Наиболее сложным представляется тест, который направлен непосредственно на определение воздействия, оказываемого на торговлю. Разрабатывая этот тест, Суд ЕС лишь дал более широкое толкование определений содержащихся в решении, которое он принял в деле STM. В этом стандартном тесте содержится толкование трех основных элементов:

а) достаточная степень вероятности, основанная на ряде объективных правовых факторов или на основе фактов;

b) оказание воздействия на торговлю между государствами - членами ЕC;

с) прямое или косвенное, фактическое или потенциальное воздействие.

Для более полного содержательного понимания всех этих терминов можно обратиться непосредственно к изданному Положению, но, мне представляется, что здесь необходимо лишь указать на то, что понятие «оказание воздействия» носит нейтральный характер, т.е. речь не идет только об отрицательном воздействии, речь также идет о положительном воздействии на торговлю, т.е. увеличении объемов или оборотов торговли. В данном случае этот термин и критерий носит

${ }^{26}$ Maher M. Dabbah, EC and UK Competition Law. Commentary, Cases and Materials. p. 80 . 
юридический, а не экономический характер,. Важно лишь наличие изменения уровня торговли, в независимости от того, позитивное это изменение или негативное.

В самом начале появления европейского права конкуренции значение «оказание воздействия» вызывало немало различных толкований относительно того, что это воздействие должно быть позитивным или негативным, или вообще нейтральным, т.е. не имело значение, какое оно - главное или нет. Вот, что пишет по этому поводу Д. Гойдер в своей работе «Право конкуренции ЕС»: «... ранние дебаты вокруг правильной интерпретации слова, связанного с «оказанием воздействия» в английском переводе статьи 81 сегодня кажется несколько академичными.

В то время, когда было всего четыре официальных языка, на которых был составлен Римский договор, было очевидно, что на голландском языке этот термин подразумевал негативное воздействие на торговлю между государствами-членами. То же самое выражение на итальянском или немецком языках было еще более непонятно по своему значению, а французское значение этого слова (affecter) имело как нейтральное, так и негативное значение.

Комбинированный эффект слегка различных смысловых оттенков перевода этого термина с четырех языков оставлял впечатление, что оказание воздействия на торговлю является нейтральным, т.е. обладающим как позитивными, так и негативными последствиями, что в свою очередь не обязательно означает, что оно подпадает под действие статьи 81(1)». Впоследствии, судебная практика подтвердила нейтральное значение этого термина.

Говоря о воздействии на торговлю между государствами - членами ЕС нельзя не упомянуть о так называемой доктрине «de minimis». Необходимо отметить, что Суд ЕС (а с 1989 года и Суд первой инстанции) применяет доктрину «de minimis», оценивая соглашения на предмет их исключения из-под действия статьи 81, - правила, согласно которому мелкие соглашения между предприятиями, не причиняющие ущерба торговле между государствами - членами ЕС и не ограничивающие свободу конкуренции, могут быть исключены из-под действия статьи $81^{27}$.

27 Зименкова О.Н. Регулирование конкурентной монополистической деятельности // Гражданское и торговое право зарубежных государств: Учебник / Отв.редактор Е.А. Васильев, А.С. Комаров. Т.1. М.: Международные отношения, 2004. - 289-290 с. 
4. Толкование понятия: «которые имеют своей целью или результатом предотвращение, ограничение или нарушение конкуренции внутри общего рынка»

Для того, чтобы соглашение подпало под действие статьи 81(1), оно по своей цели или результату (воздействию) должно ограничивать конкурентные отношения. Статья 81(1) содержит ряд целей, которые могут содержаться в соглашениях и которые автоматически признаются недействительными, т.е. ограничивающие конкурентные отношения. Речь прежде всего идет о подпунктах (а)-(е) статьи 81(1).

Но данный список ограничений не является исчерпывающим, и судебная практика постепенно добавляет в этот список иные ограничения, которые автоматически должны признаваться Европейской Комиссией, Судом ЕС и национальными судами как нарушающие статью 81(1).

Сложность с толкованием этого термина заключается в том, что антимонопольным органам ЕС и Суду ЕС необходимо было, прежде всего, прояснить для себя - является ли данный термин стремлением утвердить свою юрисдикцию (в данном случае это, прежде всего, относится к Европейской Комиссии) или обеспечить механизм для оценки соглашений, которые могут быть исключены из под действия статьи 81(1).

Причиной для возникновения такой дилеммы является изначальное по своей природе несовершенное состояние рынка и конкурентных отношений на нем. Если Европейская Комиссия и Суд ЕС будут применять и истолковывать эту норму в жестком смысле и полном соответствии с требованиями, изложенными в статье 81(1), то можно со стопроцентной уверенностью сказать, что практически все заключаемые релевантные соглашения будут подпадать под действие этой статьи. И в этой связи возникают два подхода к интерпретации, и понимаю этой нормы: жесткий и либеральный.

Жесткий подход практически запрещает все заключаемые соглашения, а либеральный подход, наоборот, дает слишком большую свободу для заключенных соглашений. Практически любой из данных подходов приводит к ограничению, устранению и искажению конкурентных отношений. Какой же выход из этой ситуации и как, прежде всего, Европейская Комиссия должна понимать и интерпретировать эту норму.

Первоначально Суд ЕС и Суд первой инстанции воспринимал эту норму как юридическую, т.е. буквально. Но практика развития конку- 
рентных отношений показала, что буквальное толкование этой нормы запрещало ряд эффективных и инновационных соглашений, которые могли внести значительный вклад в развитие, прежде всего, торговых и экономических связей между государствами - членами ЕС.

Вследствие чего, Суд ЕС стал занимать более либеральную позицию в отношении толкования этой нормы и вынесения соответствующих решений по спорным делам, а также стал использовать принцип оценки заключенных соглашений. Прежде всего, это относится к соглашениям вертикального типа и ряду видов соглашений горизонтального типа. В юридической теории, занимающейся анализом и развитием конкурентных отношений, появилось мнение, что в европейском праве конкуренции должно существовать подобие правила «положительного эффекта», которое существует в США и применяемое к статье 1 и 2 Закона Шермана. Тем не менее, нужно отметить, что данное правило не используется Судом ЕС и Суд находит возможности применять оценочный подход, используемый в правиле «положительного эффекта» в рамках пунктов 1 и 3 статьи 81. Обсуждение упомянутого правила «положительного эффекта» в контексте статьи 81(1) и особенно в контексте нормы «предотвращение, ограничение или искажение конкурентных отношений» приводит к путанице, нежели к прояснению и пониманию этого вопроса 28.

\section{Резюмируя вышесказанное нужно отметить:}

1) Статья 81(1) содержит список типов соглашений, которые автоматически признаются недействительными, т.е. нарушающими конкурентные отношения.

2) Суд ЕС и Суд первой инстанции воспринимает норму статьи 81(1) как сугубо юридическую и толкует, и соответственно выносит решения в соответствии с буквальным толкованием этой нормы.

3) В последнее время Суд ЕС стал занимать более либеральную позицию относительно применения и толкования этой нормы, и стал использовать принцип оценки рассматриваемого соглашения, в результате чего заключенное соглашение, которое по ряду формальных юридических признаков подпадает под действие статьи 81(1) может быть тем не менее не запрещено. Такого рода соглашение может быть не запрещено, если оно по своей цели и результату не подпадает под жесткие ограничения, изложенные в этой статье, т.е. фиксирует прямо или косвенно цены, раздел рынков и т.п.

${ }^{28}$ EC Competition Law, D.G. Goyder, p. 92. 
4) В апреле 2004 года Европейская Комиссия издала Положение по применению статьи 81(3), в которых, в пунктах 21-27 содержатся правила и критерии оценки заключенного соглашения, которые используются Европейской Комиссией. Данные рекомендации основываются на вынесенных ранее судебных решениях.

5) Помимо перечня типов соглашений, содержащихся в статье 81(1), которые автоматически признаются недействительными, есть также и иные типы соглашений, которые также признаются недействительными. Эти типы соглашений содержатся, например, в Положениях о вертикальных и горизонтальных соглашениях, и некоторых других положениях.

При оценке соглашения, как Европейской Комиссией, так и Судом ЕС будут иметь важное значение такие два термина, как «цель» и «результат» заключенного соглашения. Если заключенное соглашение по своей цели направлено на ограничение конкурентных отношений (например, содержит цель, которая соответствует пунктам (а)-(е) статьи 81(1), то нет необходимости проводить какие-либо исследования или оценку этого соглашения для подтверждения или демонстрации эффекта, оказываемого на рынок. Оно автоматически считается недействительным, и нет смысла доказывать его результат.

Но, если, Суд ЕС посчитает, что из соглашения не совсем понятна его цель (что бывает крайне редко), или посчитает, что оно не ограничивает конкурентные отношения, то он должен оценить результат воздействия на рынок заключенного соглашения. Нужно отметить, что термины «цель» и «результат» не являются кумулятивными, а выступают в качестве альтернативных, т.е. Суд ЕС либо должен сконцентрироваться на цели заключенного соглашения, либо на результате этого соглашения, а не одновременно устанавливать цель и результат.

В одном из своих первых решений Суд ЕС постановил, что, прежде всего, необходимо обратить внимание на цель заключенного соглашения путем рассмотрения содержащихся положений соглашения с учетом экономического контекста, в котором оно было заключено. Если после такого рассмотрения становится, очевидно, что невозможно прийти к выводу, нарушает ли это соглашение конкурентные отношения или нет, Суд ЕС должен исследовать результат от заключенного соглашения.

Исследование результата от заключенного соглашения должно также осуществляться с учетом экономического контекста, в котором оно 
было заключено, а также с учетом того, каково могло бы быть состояние релевантного рынка вследствие отсутствия рассматриваемого соглашения. При оценке результата заключенного соглашения, должно быть принято во внимание наличие фактического и потенциального эффекта на рынок. Другими словами, соглашение должно обладать очевидным антиконкурентным воздействием на рынок ${ }^{29}$. Этот эффект или воздействие на рынок может выражаться в виде фактического и потенциального негативного воздействия на цены, количество производимой продукции, внедрения инноваций, разнообразия и качества товаров или услуг, которые могли бы быть произведены или оказаны с разумной степенью вероятности.

Следует особо отметить, что оценка такого воздействия на конкурентные отношения не применяется к соглашениям, подпадающим под доктрину “de minimis” (минимального ущерба), т.е. к соглашениям, не оказывающим значительного воздействия на рынок ЕС. В своих самых ранних решениях, Суд ЕС постановил, что статья 81(1) применяется только к соглашениям, которые оказывают очевидное антиконкурентное воздействие на общий рынок. В целом считается, что негативный результат на рынок и конкурентные отношения оказывает ситуация, когда стороны, совместно или единолично обладают значительной рыночной властью на рассматриваемом рынке. И именно соглашения, заключаемые между такими субъектами экономической деятельности, способствуют укреплению и поддержанию рыночной власти.

Что же собственно составляет в общетеоретическом понятии рыночную власть? Ответ на этот вопрос можно найти в Положении по применению статьи 81(3), в пункте 25, где говорится, что рыночная власть - это возможность по поддержанию цены в течение продолжительного времени выше конкурентного уровня или поддержание уровня производства относительно количества, качества и разнообразия продукции ниже конкурентного уровня в течение продолжительного времени. Конечно же, следует иметь ввиду, что понятие рыночная власть является довольно-таки относительным и зависит от большого количества внешних факторов, которые оказывают влияние на релевантный рынок.

6) Сложившаяся в ЕС судебная и правоприменительная практика относительно применения и толкования статьи 81(1) в значительной

29 Положение по применению статьи 81(3) пункт 24. 
степени может быть позаимствована антимонопольными и судебными органами нашей страны. В частности, вследствие принятия в нашей стране нового Закона о защите конкуренции ${ }^{30}$ в котором, многие спорные вопросы, не разрешенные предыдущим Законом о конкуренции ${ }^{31}$, не нашли своего однозначного разрешения также и в новом законе. Так, представляет интерес сложившаяся практика и подходы к определению таких понятий, как «соглашение между предприятиями», «решение ассоциации предприятий», «ограничительная деловая практика». Помимо этого, на мой взгляд, представляет значительный интерес понимание содержание такой важной доктрины как “de minimis", поскольку она имеет большое практическое значение для применения ее к соглашениям, заключаемым в сфере малого предпринимательства, а также уменьшения административных и бюрократических барьеров в сфере применения антимонопольного законодательства в целом. Представляет также большой интерес подход антимонопольных и судебных органов ЕС к соглашениям, которые имеют своей целью или результатом предотвращение, ограничение или нарушение конкуренции внутри общего рынка. Данная проблема является достаточно актуальной и для нашей страны, поскольку уровень монополизации и концентрации производства в нашей экономике остается достаточно высокий и этот уровень имеет, прежде всего, региональный характер, где в силу объективных причин в том или ином регионе сосредоточено значительное количество финансовых, экономических и природных ресурсов.

30 Федеральный закон от 26 июля 2006 г. № 135-Ф3 «О защите конкуренции».

31 Закон РСФСР от 22 марта 1991г. № 948-I «О конкуренции и ограничении монополистической деятельности на товарных рынках». 


\section{Interpretation by the European Court of the Rules on Competition set out in Article 81 of the European Treaty \\ (Summary)}

Vyacheslav A. Gorbachev*

The problem of the antimonopoly regulation and stimulation of the development of competition is becoming more and more acute for our country. The principal point of difficulty in the antimonopoly regulation of the companies' activities on the market is the poorly developed competition legislation and heavily monopolized regional markets. One of the ways of solving these problems is borrowing some pro-competitive approaches and legislation that have been developed and successfully implementing in the countries with the developed open market economy with free competition, particularly in the EU.

In general, the EU rules on competition applying to undertakings include a general prohibition on cartels that results in the nullity of prohibited agreements or decisions, but that is made less harsh by the possibility of exemption (Article 81), a prohibition on the abuse of dominant positions (Article 82). However, the article is dedicated to analyzing of the most important and at the same time very controversial terms and meanings that are used in the EU competition legislation. These terms are set out in the Article 81(1) of the Rome Treaty establishing the European Community (EC Treaty). In particular this article considers the following:

1. conception of "undertaking" in terms of the competition law;

2. meaning "agreements, decisions of associations and concerted practices";

3. meaning "which may affect trade between member states";

4. meaning "which have as their object or effect the prevention, restriction or distortion of competition within the common market".

\footnotetext{
* Vyacheslav A. Gorbachev - post-graduate student of the Chair of International Private and Civil Law, MGIMO-University MFA Russia.
} 